\title{
Responding to health emergencies
}

\author{
COVID-19, climate change and the importance of primary healthcare
}

Glenn Duns

THE FUNDAMENTAL IMPORTANCE of primary healthcare has been highlighted by the COVID-19 pandemic. ${ }^{1}$ Primary healthcare is a multifaceted and comprehensive approach to health that involves multiple sectors in society, including public health responses, education, infrastructure and primary medical care. ${ }^{2}$ In the absence of a cohesive primary healthcare response to events such as the COVID-19 pandemic, acute medical care systems can be overwhelmed, with catastrophic results. ${ }^{3}$

General practice has played a central role in the pandemic response in Australia. In addition to the continuous, comprehensive and coordinated care that it always provides, general practice has been on the frontline of the public health response to COVID-19. Patients have turned to general practitioners for advice and interpretation of public health recommendations. Telehealth reforms have facilitated safe contact with vulnerable patients, and face-to-face contact under certain conditions has permitted the continuation of essential services. Ongoing contact with socially isolated patients has helped prevent many from slipping into illness.

Higher levels of anxiety and psychological distress in the general population have occurred in response to both the COVID-19 pandemic and the restrictions taken to limit its spread..$^{4,5}$ In making policy recommendations for responding to the mental health sequelae, researchers have recognised that there is a complex relationship between the economy, the education sector, physical health and mental health, and that economic responses will play a key role in mental health outcomes. ${ }^{6}$ This affirms the clinical experiences of general practitioners, as well as the multifaceted approach of primary healthcare.

The COVID-19 pandemic is not the only health emergency that Australia has faced in 2020. It was only earlier this year that Australia experienced unprecedented bushfires. Climate change has been declared the biggest global health threat of the 21st century and, like COVID-19, requires a multisectoral approach. ${ }^{7}$ Apart from immediate threats such as thermal burns, smoke from bushfires decreases air quality and results in excess deaths. ${ }^{8}$ Heatwaves in Australia are more frequent, more intense and last longer than previously, causing more deaths than any other type of natural disaster. ${ }^{9}$ Extreme weather events associated with climate change can cause psychological distress and mental illness, such as post-traumatic stress disorder. These are just a few of the direct and indirect adverse health consequences associated with climate change, ${ }^{10}$ and they are predicted to worsen if climate change continues unchecked.

Primary healthcare, with its established principles and multisectoral approach, is an ideal mechanism to provide support and care in response to health threats. A well-resourced primary healthcare system with a properly supported health workforce can protect against threats, and the emphasis on prevention that is one of the defining principles of primary healthcare can help to avert further health crises. General practice as a central facet of primary healthcare must be adequately supported to face health threats in whatever form they may take. Leadership and communication are part of our core identity as generalist health professionals, ${ }^{11}$ and we can contribute to positive changes that may occur as a result of the current crisis. ${ }^{12}$

\section{Author}

Glenn Duns MDCM, FRACGP, MPH; Medical Editor, Australian Journal of General Practice; General Practitioner, Melbourne, Vic

\section{References}

1. Primary Health Care Performance Initiative. Supporting strong PHC during the pandemic. Washington, DC: PHCPI, 2020. Available at https://improvingphc.org/covid-19 [Accessed 6 November 2020].

2. World Health Organization. Primary health care. Geneva, CH: WHO, 2019. Available at www.who. int/news-room/fact-sheets/detail/primary-healthcare [Accessed 6 November 2020].

3. Redlener I, Sachs JD, Hansen S, Hupert N. '130,000 - 210,000 avoidable covid-19 deaths - and counting - in the U.S.' New York, NY: NCDP, 2020.

4. Jurblum $\mathrm{M}, \mathrm{Ng} \mathrm{CH}$, Castle DJ. Psychological consequences of social isolation and quarantine. Aust J Gen Pract 2020;49(12):778-83.

5. Cooper J, Phelps AJ, Ng CH, Forbes D. Diagnosis and treatment of post-traumatic stress disorder. Aust J Gen Pract 2020;49(12):785-89.

6. Atkinson JA, Skinner A, Lawson K, Song Y, Hickie I. Road to recovery: Restoring Australia's mental wealth. Camperdown, NSW: University of Sydney Brain and Mind Centre, 2020.

7. A commission on climate change. Lancet 2009;373(9676):1659. doi: 10.1016/S01406736(09)60922-3.

8. Borchers Arriagada N, Palmer AJ, Bowman DM, Morgan GG, Jalaludin BB, Johnston FH. Unprecedented smoke-related health burden associated with the 2019-20 bushfires in eastern Australia. Med J Aust 2020;213(6):282-83. doi: 10.5694/mja2.50545.

9. Steffen W, Hughes L, Perkins S. Heatwaves: Hotter, longer, more often. Potts Point, NSW: Climate Council of Australia, 2014.

10. Doctors for the Environment Australia. Climate change and health in Australia: Fact sheet. Carlton, Vic: DEA, 2016.

11. Shaw E, Oandasan I, Fowler N, eds. CanMEDS-FM 2017: A competency framework for family physicians across the continuum. Mississauga, ON: The College of Family Physicians of Canada, 2017.

12. Doctors for the Environment Australia. \#HealthyRecovery joint letter in the news. Carlton, Vic: DEA, 2020. Available at www.dea.org.au/ healthyrecovery-joint-letternbsp [Accessed 6 November 2020]. 